\title{
Frustration Still Exists
}

\author{
Hyun Shig Kim \\ Department of Surgery, Seoul Song Do Colorectal Hospital, Seoul, Korea
}

\section{See Article on Page 222-227}

The history of colonoscopy could be the history of bowel preparation. In fact, the evolution of bowel preparation is much longer than the history of colonoscopy. Bowel preparation was also inevitable in the era of radiological colon study. Along with the progress in colonoscopy, various studies of bowel preparation have been done. The main emphases of those bowel-cleansing studies were drugs or regimens and administration methods. A single agent or combined regimens have been tried in various ways. In fact, the agents are not as diverse as the colonoscopic procedures. An unavoidable limitation of drugs or agents is that must they do no harm to the human body and be sufficiently effective [1].

This article addresses the single and the combined use of a polyethylene glycol solution and a sodium picosulfate with magnesium citrate solution. The authors reported good results for the sodium picosulfate/magnesium citrate solution, even for its single use [2]. Sodium picosulfate with magnesium citrate is not a novel agent and has already been reported to be an efficient precolonoscopy bowel-preparation agent [3].

However, the study is still worthwhile because the importance of bowel preparation cannot be underestimated in any practical colonoscopies. In other words, bowel cleansing is the basic procedure for successful colonoscopic diagnosis and treatment. Many patients used to say that the colonoscopy itself was bearable, but the process of bowel preparation was a real pain. That was reality! Bowel cleansing is time consuming, uncomfortable and stressful. As a matter of fact, despite the existence of various bowel-cleans-

Correspondence to: Hyun Shig Kim, M.D.

Department of Surgery, Seoul Song Do Colorectal Hospital, 72 Dasan-ro, Jung-gu, Seoul 100-450, Korea

Tel: +82-2-2250-7368, Fax: +82-2-2233-8528

E-mail:mdkhs@hotmail.com

(C) 2014 The Korean Society of Coloproctology

This is an open-access article distributed under the terms of the Creative Commons Attribution NonCommercial License (http://creativecommons.org/licenses/by-nc/3.0) which permits unrestricted noncommercial use, distribution, and reproduction in any medium, provided the original work is properly cited. ing methods, we still experience frustrating situations for patients and even for doctors. Accordingly studies should be continued. Although the efficacies of the drugs and of the administration methods are the key points, practical points, such as the planned timetable and schedules, could be obstacles to bowel cleansing.

In short, frustration still exists in bowel preparation. A tailored approach could be helpful. Patience and sincerity are needed for colonoscopists, assisting staff members and patients themselves. The basic principle is important and still remains as an issue.

\section{REFERENCES}

1. Park JB, Lee YK, Yang CH. The evolution of bowel preparation and new developments. Korean J Gastroenterol 2014;63:268-75.

2. Song KH, Suh WS, Jeong JS, Kim DS, Kim SW, Kwak DM, et al. Effectiveness of sodium picosulfate/magnesium citrate (PICO) for colonoscopy preparation. Ann Coloproctol 2014;30:222-7.

3. Love J, Bernard EJ, Cockeram A, Cohen L, Fishman M, Gray J, et al. A multicentre, observational study of sodium picosulfate and magnesium citrate as a precolonoscopy bowel preparation. Can J Gastroenterol 2009;23:706-10. 